\title{
Assessment of tamoxifen effects on nitric oxide synthase (nNOS) in rat developing hippocampus
}

\author{
Maliheh Nobakht*1, Maasoumeh Shafiee ${ }^{2}$ and Parvaneh Tabatabaeei ${ }^{1}$
}

\author{
Address: ${ }^{1}$ Department of Anatomy, Histology and Neuroscience, School of Medicine, Iran University of Medical Science, 14155-6183 Tehran, Iran \\ and ${ }^{2}$ Department of Pharmacology, School of Medicine, University of Medical Science, 14155-6183 Tehran, Iran \\ Email: Maliheh Nobakht* - manob@iums.ac.ir \\ * Corresponding author
}

from Seventeenth Annual Computational Neuroscience Meeting: CNS*2008

Portland, OR, USA. 19-24 July 2008

Published: II July 2008

BMC Neuroscience 2008, 9(SuppI I):P64 doi:I0.I I86/I47I-2202-9-SI-P64

This abstract is available from: http://www.biomedcentral.com/I47I-2202/9/SI/P64

(C) 2008 Nobakht et al; licensee BioMed Central Ltd.

\section{Background}

Maternal steroids modulate various functions in the developing brain. Tamoxifen (TAM) treatment, as an estrogen antagonist, induced cell death in the rat developing hippocampus. Estrogen has a variety of physiological effects in the nervous system, including regulation of cognitive functions, learning, aging, angiogenesis and neurogenesis as well as neuroprotective effects.

\section{Aim}

In the present study, we demonstrated the effects of TAM as an estrogen antagonist on nitric oxide synthase activity in the rat developing hippocampus pyramidal neurons.

\section{Materials and methods}

The present description is based on twelve adult rats. The animals were divided randomly into control, experimental and sham groups. In each, we have full term embryo $\left(\mathrm{E}_{22}\right), 1$ day neonate $\left(\mathrm{P}_{1}\right)$, one week neonate $\left(\mathrm{P}_{7}\right)$ and three weeks neonate $\left(\mathrm{P}_{21}\right)$. In experimental groups animals at full term received four doses of the $(250 \mu \mathrm{g} / \mathrm{kg}$ in propylene glycol i.p. twice a day for a total of four doses). The hippocampus was removed 6 hours after the last injection. Animals at the same gestational age were used as sham and controls. Controls received only propylene glycol. The hippocampus was dissected out and stored in fixative and sucrose. Cryostat sections were thawmounted on gelatin slides. The sections were incubated for NADPH-diaphorase histochemistry by light microscopy.

\section{Results}

We found that in the earliest stage of development the cellular density is low and there was a gradual increase in cellular thickness, with maximum thickness observed after third weeks. The short half-life of tamoxifen can change $\mathrm{E}_{22}, \mathrm{P}_{1}$ and $\mathrm{P}_{7}$. The effect of treatment without tamoxifen, due to existence of estrogen, is characterized by strong NADPH-diaphorase activity that showed NOS activity. With treatment with tamoxifen, in the early stages, we found significant decreases in NADPH-diaphorase reactivity following estrogen receptor blockade. Furthermore, we demonstrated a decreased activity of NOS in the CA1 hippocampal region and reduced neuronal cell numbers. The decreased activity of NOS and reduced hippocampal cell numbers were observed in $\mathrm{E}_{22}$ and one day neonate and one week neonate.

\section{Conclusion}

Evidence so far suggests that this phenomenon may be the result of the short half-life of tamoxifen. These findings indicate that estrogen and selective estrogen modulators can influence nitric oxide-mediated growth and development in pyramidal cells. 